\title{
Endogenous cycles from income diversity, capital ownership, and differential savings
}

\author{
Anna Agliari ${ }^{\mathrm{a}, *}$, Volker Böhm ${ }^{\mathrm{b}}$, Nicolò Pecora ${ }^{\mathrm{a}}$ \\ a Dept. of Economics and Social Science, Catholic University, Via Emilia Parmense 84, Piacenza 29100, Italy \\ ${ }^{\mathrm{b}}$ Center for Mathematical Economics (IMW) and Dept. of Business Administration and Economics, Bielefeld University, Universitätsstraße 25 D-33615, \\ Bielefeld, Germany
}

\section{A R T I C L E I N F O}

\section{Article history:}

Received 29 March 2019

Revised 9 September 2019

Accepted 10 September 2019

\section{JEL classification:}

C62

D24

E32

042

Keywords:

Capital ownership

Income diversity

Differential savings

Neimark-Sacker bifurcation

Homoclinic tangles

Multistability

\begin{abstract}
A B S T R A C T
Endogenous cycles in standard growth models with capital accumulation of the Solow or the OLG type occur only when there is some degree of heterogeneity among consumers, differential savings, income diversity, or market specialization. Otherwise, without income effects or distribution effects long run steady states are mostly asymptotically stable predicting stable balanced growth for many of the commonly accepted growth models under most aggregative concave neoclassical production functions.

This paper provides an attempt to exhibit a full richness of bifurcation scenarios for endogenously generated cycles using minimal extensions concerning preferences, technologies, and ownership of capital by extending the models of Kaldor, Pasinetti, and others to allow for ownership of capital among OLG consumers of workers and capitalists.

It is shown that, under a sufficiently low but constant elasticity of substitution, the interaction of the nonlinear income distribution with heterogeneous logarithmic intertemporal preferences of consumers causes a variety of local bifurcation scenarios (Neimark-Sacker, fold, period doubling), multi-stability, as well as a rich variety of complex global dynamic features, such as homoclinic tangles, periodicity regions originating from Arnold tongues, closed curve attractors, and complex basins. The paper provides a detailed numerical analysis under a CES production scenario of several global bifurcations arising from heterogeneity which does not exist under the specific ownership restrictions imposed in the original Kaldor/Pasinetti models.
\end{abstract}

(c) 2019 Elsevier Ltd. All rights reserved.

\section{Introduction}

Endogenous cycles in neoclassical growth models with capital accumulation either of the Solow/Swan type [24,27] or with overlapping generations of consumers (the OLG type) occur only when there is differential savings, i.e. under behavioral heterogeneity among consumers and a nonconstant functional income distribution between wages and capital returns along the growth path. Without differential behavior or distributional variations of incomes, long run steady states in such models are typically asymptotically stable predicting noncyclical convergence to balanced growth paths for many of the commonly discussed growth models under most aggregative concave neoclassical production functions [3]. The issue of differential savings between groups of agents was

\footnotetext{
* Corresponding author.

E-mail addresses: anna.agliari@unicatt.it (A. Agliari), vboehm@wiwi.unibielefeld.de (V. Böhm), nicolo.pecora@unicatt.it (N. Pecora).
}

originally posed within the Harrod-Domar model [11] while the work by Stiglitz JE. [25] considered the Solow model and analyzed how different savers' wealth and income evolved. More recently, $[5,6]$ investigated the neoclassical growth model of the Solow type where the different saving rates of workers and capitalists is coupled with a endogenous labor force growth rate. Another paper that also bears resemblance to the present one is [7] whose authors, starting from the Solow-Pasinetti growth model, depart from the original setup by considering two types of agents, namely capitalists and workers, who have different saving decisions based on an optimizing behaviour. In particular, an infinitely lived dynasty of capitalists saves on the basis of an altruistic motive, while workers' savings decisions are driven by a life-cycle motive. Three types of long-run equilibria are found and their stability properties are analyzed. Moreover, flip and Neimark-Saker bifurcations can also occur depending on the degree of substitutability between productive factors, giving rise to complex and eventually chaotic dynamics

Thus, when introducing modifications in these areas, the complexity of the ensuing scenarios of cycles and bifurcations always 
depend on the interaction of the degree or strength of the deviations from homogeneity in the savings behavior and from the isoelastic production functions. Most papers on economic growth considering the neoclassical model used the Cobb-Douglas specification of the production function, which describes a process with a constant elasticity of substitution between production factors equal to one. With this formulation the system monotonically converges to the steady state (i.e. the capital per capita equilibrium) so neither cycles nor complex dynamics can be exhibited. In this respect, many papers have examined the role of the elasticity of substitution for the long-run behavior of the economy and the speed of convergence to the balanced growth path [see, e.g., [15,16,20]], especially by considering the Constant Elasticity of Substitution (CES) production function. The elasticity of substitution between production factors turns out to be relevant since it represents one of the determinants of the economic growth level. Accordingly, in the present work, when dealing with a specific technology, we shall also make use of the CES production function since it can account for the presence of growth cycles.

This paper provides an attempt to exhibit a full richness of possible bifurcation scenarios for endogenously generated cycles using minimal extensions concerning preferences, technologies, and ownership of capital by extending the models of $[13,14,21,23]$ and others to allow for general ownership of capital among OLG consumers of workers and capitalists.

The paper analyzes the impact of differential savings behavior due to heterogeneity of consumers in growing economies with overlapping generations of two types of consumers, workers and capitalists, who own the capital in the economy. Constant profit shares of capital owners induce a two-dimensional model of capital accumulation with a three-class ownership structure of capital implying a generalization of the growth models by Kaldor and Pasinetti.

When factor substitution is low under a CES technology the relative income distribution between factor shares is a monotonic function of aggregate capital with a sigmoid shape of the wage function and a unimodal function of the return to capital. In this case three different savings propensities influence the dynamics in a crucial way with dynamic features beyond the models by Kaldor and Pasinetti.

The focus of our paper is on the extension of the KaldorPasinetti framework along three directions: the introduction of the different saving propensities, the incomplete profit control of young capitalists, and the CES production function. These elements constitute the core of our model capable to generate growth cycles and endogenous fluctuations, which are of relevance when explaining the emergence of phases of growth followed by phases of recession in the course of the real economy.

It is shown that under sufficiently low but constant elasticity of substitution the interaction of the nonlinear income distribution with heterogeneous logarithmic intertemporal preferences of consumers causes a variety of local bifurcation scenarios (Neimark-Sacker, fold, period doubling), multi-stability, as well as a rich variety of complex global dynamic features, such as homoclinic tangles, periodicity regions originating from Arnold tongues, closed curve attractors, and complex basins. The paper provides a detailed numerical analysis of several global bifurcations arising from heterogeneity which cannot exist in the Kaldor/Pasinetti model.

The rest of the paper is organized as follows: Section 2 describes the generic model and presents the conditions for the existence of steady states; Section 3 introduces a specific production function and reports the local stability conditions of the steady state; in Section 4 numerical simulations present the emergence of endogenous growth cycles and complex dynamics; Section 5 concludes.

\section{Heterogeneous consumers: workers and capitalists}

We consider an extension of the standard neoclassical onesector growth model in the spirit of [12,13] and [21] by assigning capital ownership to heterogeneous cohorts of overlapping generations of consumers in the spirit of [22] and [8]. Two types of consumers populate the economy, namely workers $W$ and capitalists $C$, with equal group size each growing at the same rate $n>-1$. Both groups live for two consecutive periods, called young and old, and have logarithmic intertemporal preferences, implying a constant saving propensity $0 \leq \tilde{s}_{w} \leq 1$ and $0 \leq \tilde{s}_{c} \leq 1$ (independent on expectations on capital returns) out of total income when young.

Workers supply one unit of labor when young and consume in both periods; when young, they receive income from working (as competitive wage) plus a share $0 \leq d_{w} \leq 1$ of current capital return (marginal product of capital) from capital ownership; additionally, they finance their second period consumption by saving/investing into capital when young. Likewise, young capitalists receive a share $0 \leq d_{s} \leq 1$ of capital income from ownership of capital as well to finance their second period consumption by saving/investing into capital.

The capital is embodied in the single firm and it depreciates at the rate $0 \leq \delta \leq 1$. The ownership of capital is divided among old workers and capitalists, that is $K^{w}$ and $K^{c}$. Moreover, old consumers (either workers or capitalists) receive a share $\left(1-d_{w}\right)$ and $\left(1-d_{c}\right)$, respectively, of the current return on capital (the profit), while the shares $d_{w}$ and $d_{c}$ are paid to the respective young generations. The ownership of a firm can be transferred either by bequests or by selling to the young. In particular, with bequests no compensation between young and old is paid, while, with a capital market, the young generations of workers and capitalists purchase the depreciated capital $(1-\delta) K^{w}$ and $(1-\delta) K^{c}$ respectively from the old generations. Thus, at each date in time, the economy is a standard private ownership economy with given capital equipment and labor force which operates under competitive conditions and full employment at a stationary profit distribution given by $0 \leq\left(d_{w}\right.$, $\left.d_{c}\right) \leq 1$.

Let $L_{t}$ denote the total number of workers, $K_{t}=K_{t}^{c}+K_{t}^{w}$ the distribution of capital $\left(K_{t}^{c} \geq 0\right.$ and $\left.K_{t}^{w} \geq 0\right)$ and $Y_{t}=F\left(K_{t}, L_{t}\right)=$ $L_{t} f\left(K_{t} / L_{t}\right)$ the production function which is homogeneous of degree one and concave. It is assumed that the wage rate equals the marginal product of labor, that is

$W_{t}=f\left(k_{t}\right)-k_{t} f^{\prime}\left(k_{t}\right)$,

and the competitive rate of return equals the marginal product of capital, i.e.

$R_{t}=f^{\prime}\left(k_{t}\right)$.

Hence, the gross savings of young consumers, workers and capitalists, are respectively given by

$S^{w}=\tilde{s}_{w}\left[W_{t}+d_{w} R_{t} K_{t}^{w} / L_{t}\right]=\tilde{s}_{w}\left(f\left(k_{t}\right)-k_{t} f^{\prime}\left(k_{t}\right)+d_{w} f^{\prime}\left(k_{t}\right) k_{t}^{w}\right)$

$S^{c}=\tilde{s}_{c} d_{c}\left(R_{t} K_{t}^{c} / L_{t}\right)=\tilde{s}_{c} d_{c} f^{\prime}\left(k_{t}\right) k_{t}^{c}$

with $k_{t}^{i}:=K_{t}^{i} / L_{t}, i=w, c$ and $k_{t}^{c}+k_{t}^{w}=k_{t}$.

Let us define $s_{w}:=\tilde{s}_{w}, s_{p}:=d_{w} \tilde{s}_{w}, s_{c}:=d_{c} \tilde{s}_{c}$. Then, the capital accumulation laws for the two groups are given by the following equations

$k_{t+1}^{c}=\frac{1}{1+n}\left[(1-\delta) k_{t}^{c}+s_{c} k_{t}^{c} f^{\prime}\left(k_{t}\right)\right]$

$k_{t+1}^{w}=\frac{1}{1+n}\left[(1-\delta) k_{t}^{w}+s_{w}\left(f\left(k_{t}\right)-k_{t} f^{\prime}\left(k_{t}\right)\right)+s_{p} k_{t}^{w} f^{\prime}\left(k_{t}\right)\right]$. 
Table 1

Savings propensities, shares of profits, and capital distributions in parametric growth models.

\begin{tabular}{llll}
\hline & $d_{w}=0$ & $0<d_{w}<1$ & $d_{w}=1$ \\
\hline \multirow{2}{*}{$d_{c}=0$} & $\delta=1$, all profits consumed & & $s_{c}=s_{w}=s_{p}$ \\
& DIAMOND & SOLOW \\
$0<d_{c}<1$ & & $0<\left(d_{c}, d_{w}\right)<1$ & \\
& & $s_{p} \geq s_{c} s_{w}$ & \\
$d_{c}=1$ & OLG with capital ownership & \\
& $s_{c} \neq s_{w} ; s_{p}=0$ & & $s_{c} \neq s_{w} ; s_{w}=s_{p}$ \\
& KALDOR & & PASINETTI \\
\hline
\end{tabular}

They constitute a two-dimensional discrete time dynamical system in the state variables $k_{t}^{c}$ and $k_{t}^{w}$, for any profit distribution $0 \leq\left(d_{c}\right.$, $\left.d_{w}\right) \leq 1$ and with parameters $n>0$ (population growth rate), $\delta$ (capital depreciation rate), $s_{c}$ (saving propensity of capitalists), $s_{w}$ (savings propensity on workers' wage income) and $s_{p}$ (saving propensity on workers' profit income). Table 1 displays the relationship between four standard neoclassical models of economic growth as boundary cases of parameters of the current generalization. The labels DIAMOND, SOLOW, KALDOR, and PASINETTI identify the four original models of these authors as cases with specific profit distributions of private ownership economies (in the Arrow-Debreu sense) with OLG consumers and producers using embodied capital.

Some parameter restrictions apply for our analysis. Since the payout ratio $d_{w}$ is typically less than one, $0<s_{p}<s_{w}$ holds. Therefore, accumulation occurs as if workers save with different propensities from their two income sources, wage and profit. Then, depending on whether a capital market exists or not, the dynamical system has essentially three $\left(s_{c}, s_{w}, s_{p}\right)$ or four relevant parameters $s_{c}, s_{w}, s_{p}, \delta$ ). This implies a rich economic structure of the interaction between profit distributions and savings/investment decisions when $0<d_{w}, d_{c}<1$. The situation with $0<d_{c}=d_{w}<1$ analyzed in detail in this paper seems to be an interesting special case. However, this imposes restrictions on the range of $\left(s_{c}, s_{w}, s_{p}\right)$. The equalities $s_{p}=d_{w} \tilde{s}_{w}$ and $s_{c}=d_{c} \tilde{s}_{c}$ imply

$s_{p}=d s_{w}=\frac{s_{c}}{\tilde{s}_{c}} s_{w} \geq s_{c} s_{w}$.

\subsection{Existence of steady states: general results}

In general notation, for any concave differentiable production function $f$, the map defined by (3) and (4) can be written with state variables $\left(k_{t}^{c}, k_{t}^{w}\right)$ as

$T:\left\{\begin{array}{l}k_{t+1}^{c}=\frac{1}{1+n}\left[(1-\delta) k_{t}^{c}+s_{c} k_{t}^{c} f^{\prime}\left(k_{t}\right)\right] \\ k_{t+1}^{w}=\frac{1}{1+n}\left[(1-\delta) k_{t}^{w}+s_{w}\left(f\left(k_{t}\right)-k_{t} f^{\prime}\left(k_{t}\right)\right)+s_{p} k_{t}^{w} f^{\prime}\left(k_{t}\right)\right]\end{array}\right.$

The associated possible steady states are characterized in the following proposition.

Proposition 1. The map $T$ may exhibit steady states $\left(0, k^{w s}\right)$, called Solow equilibria, ${ }^{1}$ defined by solution(s) $k^{w s}>0$ of

$\frac{f\left(k^{w}\right)}{k^{w}}=\frac{n+\delta}{s_{w}\left(1-e_{f}\left(k^{w}\right)\right)+s_{p} e_{f}\left(k^{w}\right)}$,

where $e_{f}\left(k^{w}\right):=k^{w} f^{\prime}\left(k^{w}\right) / f\left(k^{w}\right)$ is the elasticity of the production function $f$ evaluated at $k^{w}$.

In addition, if

$$
\begin{array}{r}
\left(1-e_{f}\left(k^{*}\right)\right)\left(s_{c}-s_{p}\right)>0 \\
\left(s_{c}-s_{p}\right) e_{f}\left(k^{*}\right)-s_{w}\left[1-e_{f}\left(k^{*}\right)\right]>0,
\end{array}
$$

\footnotetext{
${ }^{1}$ We call a Solow equilibrium a steady state in which capital ownership is concentrated in only one group, i.e. in the group of workers.
}

there exists a unique steady state $\left(k^{c *}, k^{w *}\right)=\left(k^{*}-\right.$ $\left.k^{w *}, \frac{s_{w}}{s_{c}-s_{p}} \frac{1-e_{f}\left(k^{*}\right)}{e_{f}\left(k^{*}\right)} k^{*}\right) \gg 0$, called a Pasinetti equilibrium, ${ }^{2}$ satisfying $k^{*}=k^{c *}+k^{w *}$ and

$f^{\prime}\left(k^{*}\right)=\frac{n+\delta}{s_{c}}$.

Finally, an additionally boundary equilibrium $\left(k^{c * *}, 0\right)$ exists when $e_{f}\left(k^{c * *}\right)=1$.

Proof. It is immediate to observe that the $k^{w}$-axis is trapping for the map $T$, that is, $T\left(0, k^{w}\right)=\left(0, k^{w}\right)$. In fact, the one-dimensional map describing the capital accumulation in the economy where only workers are acting is the restriction to the $k^{w}$-axis of the map $T$ in (6), i.e.

$$
\begin{aligned}
k_{t+1}^{w} & =g\left(k_{t}^{w}\right) \\
& =\frac{1}{n+1}\left[(1-\delta) k^{w}+s_{w}\left(f\left(k^{w}\right)-k^{w} f^{\prime}\left(k^{w}\right)\right)+s_{p} k^{w} f^{\prime}\left(k^{w}\right)\right]
\end{aligned}
$$

It is immediate to observe that the trivial steady state $k^{w}=0$ exists iff $f(0)=0$. Moreover, if they exist, the non-trivial Solow equilibria are the solutions of the equation

$\frac{f\left(k^{w}\right)}{k^{w}}=\frac{n+\delta}{s_{w}\left(1-e_{f}\left(k^{w}\right)\right)+s_{p} e_{f}\left(k^{w}\right)}$.

A further steady state $\left(k^{c *}, k^{w *}\right) \gg 0$, labeled Pasinetti equilibrium, is given by the solutions of

$$
\left\{\begin{array}{ll}
f^{\prime}\left(k^{c}+k^{w}\right) & =\frac{n+\delta}{s_{c}} \\
(n+\delta) k^{w}-s_{p} \frac{n+\delta}{s_{c}} k^{w} & =f\left(k^{c}+k^{w}\right) s_{w}\left(1-e_{f}\left(k^{c}+k^{w}\right)\right)
\end{array} .\right.
$$

Setting $k^{*}$ the solution of

$f^{\prime}(k)=\frac{n+\delta}{s_{c}}$

we end up with the following equilibrium

$\left(k^{c *}, k^{w *}\right)=\left(k^{*}-k^{w *}, \frac{s_{w}}{s_{c}-s_{p}} \frac{1-e_{f}\left(k^{*}\right)}{e_{f}\left(k^{*}\right)} k^{*}\right)$

which is positive if

$$
\begin{aligned}
\left(1-e_{f}\left(k^{*}\right)\right)\left(s_{c}-s_{p}\right) & >0 \\
\left(s_{c}-s_{p}\right) e_{f}\left(k^{*}\right)-s_{w}\left[1-e_{f}\left(k^{*}\right)\right] & >0 .
\end{aligned}
$$

Finally, it is straightforward to see that system (9) admits an additional solution when $k^{w}=0$ and $e_{f}\left(k^{c}\right)=1$.

Our results on existence and stability of steady states are in accordance with those provided by Böhm $\mathrm{V}$ et al. [3] and by Brianzoni $\mathrm{S}$ et al. [5,6]. In fact, our model may also feature multiple steady states depending on the savings propensities (e.g. when capitalists save more than workers) which reflect the different consumer preferences. Finally, we remark that it is possible to obtain

\footnotetext{
2 We call a Pasinetti equilibrium a steady state in which capital ownership is strictly divided among workers and capitalists.
} 
the stability conditions of the steady states for the general case. However, for the sake of exposition, we restrict ourselves to the parametric case outlined in detail in the next section.

\section{Dynamics with the CES production function}

For the remaining analysis we shall consider a production function with constant elasticity of substitution, the so-called CES production function, given in its intensive form by

$f(k)= \begin{cases}A\left(1-b+b k^{\rho}\right)^{\frac{1}{\rho}}, & \rho \leq 1, \quad \rho \neq 0 \\ A k^{b} & \rho=0\end{cases}$

where $A>0$ represents the total factor productivity, $0<b<1$ denotes a distribution factor, and $\sigma=1 /(1-\rho)$ is the elasticity of substitution. Its unique analytical form was derived by Arrow K, et al. [2] describing the class of all homogeneous production functions with two input factors and constant elasticity $\sigma=1 /(1-\rho)$, including as special cases the Cobb-Douglas production function $(\rho=0)$ and the Leontiev production function for zero substitutability as $\rho \rightarrow-\infty$.

The CES production function has been an important and one of the most frequently used homogeneous functions in many areas of economic theory to elicit the role of relative price effects and of factor shares in competitive environments depending on the curvature of associated level curves of concave homogeneous functions, in particular in production theory, in duality studies of cost minimization and profit maximization, and in growth theory [for example 15,28].

The economic motivation behind the definition of $\sigma(k) \equiv$ $1 /(1-\rho)$ stems from the fact that it is equal to the elasticity of the cost-minimizing input demand $k \equiv K / L$ of a change in relative factor prices $W / R=\left(f-k f^{\prime}\right) / f^{\prime}$, which is identical to the inverse of the elasticity of the monotonically increasing function $\left(f(k)-k f^{\prime}(k)\right) / f^{\prime}(k)$ of supporting relative factor prices. The CES function captures these relationships in a transparent parametric form ( $b$ versus $\rho$ ) which reveals one of the sources of the complex dynamic behavior for the numerical analysis.

Let

$e_{f}(k):=\frac{k f^{\prime}(k)}{f(k)}=\frac{b k^{\rho}}{1-b+b k^{\rho}}$

denote the elasticity of the production function $f$ evaluated at $k$ and

$e_{f^{\prime}}(k):=\frac{k f^{\prime \prime}(k)}{f^{\prime}(k)}=(1-\rho)\left(e_{f}(k)-1\right)$

the elasticity of its first derivative. The elasticity of substitution $\sigma(k)$ of $f$, as a scale-invariant measure of curvature of the unit isoquant of the homogeneous production function $F(K, L) \equiv L f(K / L)$, is defined as the ratio of two elasticities

$\sigma(k):=\frac{1-e_{f}(k)}{-e_{f^{\prime}}(k)}=\frac{1}{1-\rho}$.

Its constancy for the form (11) justifies its name. In addition, $\rho=0$ marks the special case with $e_{f}(k)=b, e_{f^{\prime}}(k)=b-1$, and $\sigma(k)=1$ for all $k>0$. Since $e_{f}(k)$ is the share of capital income, this is a monotonically increasing (decreasing) function in $k$ for $\rho>0$ $(\rho<0)$. Thus, all income fluctuations of labor and capital move one-to-one but in opposite direction with the aggregate capital intensity $k$. For the remainder of the analysis only negative values of $\rho$, i.e. elasticities of substitution less than one, are considered. Only those imply the necessary income variations favoring capital returns which induce complex dynamical effects in the aggregative growth model.
For the CES production function the map (6) specializes to:

$$
T:\left\{\begin{aligned}
k_{t+1}^{c}= & \frac{b{k_{t}}^{\rho-1}\left(b{k_{t}}^{\rho}-b+1\right)^{\frac{1}{\rho}-1} s_{c} k_{t}^{c} A+(1-\delta) k_{t}^{c}}{n+1}, \\
k_{t+1}^{w}= & \frac{1}{n+1} s_{w}\left(\left(b{k_{t}}^{\rho}-b+1\right)^{\frac{1}{\rho}} A-b{k_{t}}^{\rho-1}\left(b k_{t}{ }^{\rho}-b+1\right)^{\frac{1}{\rho}-1} k_{t}^{c} A\right) \\
& +\frac{1}{n+1}\left(b k_{t}^{\rho-1}\left(b k_{t}^{\rho}-b+1\right)^{\frac{1}{\rho}-1}\left(s_{p}-s_{w}\right) k_{t}^{w} A+(1-\delta) k_{t}^{w}\right) .
\end{aligned}\right.
$$

\subsection{Existence and stability of steady states}

Let $\rho<0$ and consider first the conditions for the existence of Solow equilibria. ${ }^{3}$ Recalling Proposition 1 , condition (8) which defines Solow equilibria now reads

$A\left(s_{w}(1-b)+s_{p} b\left(k^{w}\right)^{\rho}\right)\left(1-b+b\left(k^{w}\right)^{\rho}\right)^{\frac{1}{\rho}-1}=(n+\delta) k^{w}$.

Calling the left hand side of the previous equation $h\left(k^{w}\right)$, it is possible to show that, under the hypothesis of $s_{w}>s_{p}, h(0) \rightarrow 0, h\left(k^{w}\right)$ has a horizontal asymptote (i.e. it is bounded) and it is increasing. Since the sign of $h^{\prime \prime}\left(k^{w}\right)$ is not constant, we have to distinguish two possibilities.

In the first case, if $\rho s_{w}+(1-\rho) s_{p}>0$, the function $h\left(k^{w}\right)$ is concave. Then, there exists a unique Solow equilibrium if $h^{\prime}(0)>$ $n+\delta$. Taking the two conditions together, the unique Solow steady state exists if

$s_{p}>\max \left\{\frac{-\rho}{1-\rho} s_{w}, \frac{n+\delta}{A b^{1 / \rho}}\right\}$.

In Fig. 1(a), $h\left(k^{w}\right)$ is concave and only one Solow fixed point exists. The black line represents the function $(n+\delta) k^{w}$. In the second case, i.e. when $\rho s_{w}+(1-\rho) s_{p}<0$, the function $h\left(k^{w}\right)$ is $S$ shaped. Accordingly one, no, or two positive steady states exist. In particular, equilibria arise when the function $h\left(k^{w}\right)$ first lies below the straight line $(n+\delta) k^{w}$, i.e. when $s_{p}<\frac{n+\delta}{A b^{1 / \rho}}$, and then becomes tangent to it. This occurs at

$s_{p}=s_{p}^{\tan }=s_{w}-\frac{(n+\delta)^{\rho}(1-\rho)^{\rho-1} s_{w}^{1-\rho}}{A^{\rho} b(-\rho)^{\rho}}$.

When $s_{p}>s_{p}^{\tan }$ two steady states exist. This situation persists until $h^{\prime}(0)=n+\delta$ and one steady state merges with the trivial equilibrium (transcritical bifurcation). To sum up the conditions for the existence of the "Solow type" equilibria we can state that

one equilibrium exists if $\quad \frac{n+\delta}{A b^{1 / \rho}}<s_{p}$,

two equilibria exist if

$$
s_{p}^{\text {tan }}<s_{p}<\frac{n+\delta}{A b^{1 / \rho}}
$$

no equilibria otherwise.

Since $k^{w}=0$ is invariant for the map, the Jacobian matrix evaluated at the Solow steady state is triangular. It is easy to obtain that the eigenvalue associated with the direction of the $k^{w}$-axis is

$\lambda_{\|}=\frac{e_{f}\left(k^{s}\right) s_{c}}{e_{f}\left(k^{s}\right) s_{p}+s_{w}\left(1-e_{f}\left(k^{s}\right)\right)}$

and the one associated with the transverse direction is

$\lambda_{\perp}=\frac{e_{f}\left(k^{s}\right)\left(\left(e_{f}\left(k^{s}\right)+1\right) s_{p}-e_{f^{\prime}}\left(k^{s}\right) s_{w}\right)}{e_{f}\left(k^{s}\right) s_{p}+s_{w}\left(1-e_{f}\left(k^{s}\right)\right)}$

\footnotetext{
${ }^{3}$ The condition for the existence of the boundary equilibrium $\left(k^{c * *}, 0\right)$, i.e. $e_{f}\left(k^{c}\right)=1$, when considering a CES production function translates into $b=1$, which is a value that such parameter can not assume, since the distribution factor only takes value $0<b<1$.
} 


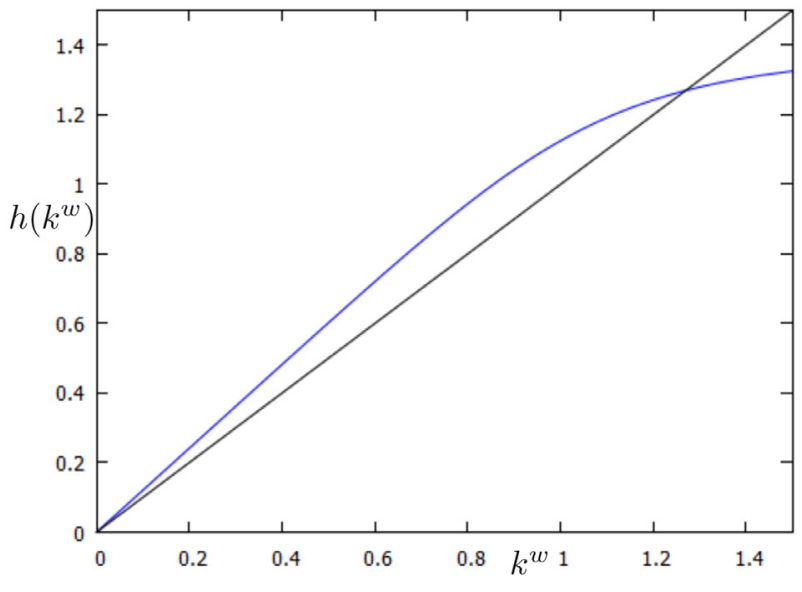

(a) $s_{p}=0.2$

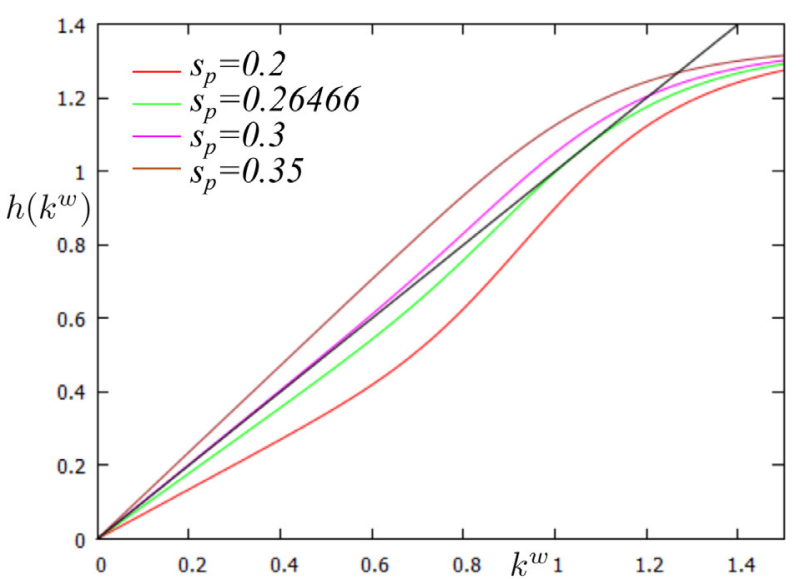

(b) $s_{p}=0.2 ; 0.26466 ; 0.3 ; 0.35$

Fig. 1. The role of $s_{p}$ on the function $h\left(k^{w}\right) ; n=0, \delta=1, A=3, \rho=-6, b=0.5, s_{w}=0.4$.

and to see that they are both positive. Hence, any Solow equilibrium is locally stable if

$$
\left\{\begin{array}{l}
\operatorname{stab}_{1}=e_{f}\left(k^{s}\right)(1-r h o)\left(s_{w}-s_{p}\right)-s_{w}<0 \\
\operatorname{stab}_{2}=1-e_{f}\left(k^{s}\right)\left(s_{p}-s_{c}\right)+s_{w}\left(1-e_{f}\left(k^{s}\right)\right)>0
\end{array}\right.
$$

The crossing of the curve $s t a b_{1}=0$ corresponds to a fold bifurcation which gives rise to two steady states since, the $s_{p}^{\text {tan }}$ value satisfies such equation being $e_{f}\left(k^{s}\right)=b\left[A b \rho\left(s_{p}-s_{w}\right)\right]^{\rho /(1-\rho)}$ at the bifurcation. Instead, the bifurcation occurring at the crossing of $s t a b_{2}=0$ is a transcritical one as we shall see below.

Turning to the existence of Pasinetti equilibria with the CES production function, let the assumptions of Proposition 1 hold. A Pasinetti equilibrium $\left(k^{c *}, k^{w *}\right) \gg 0$ is given by

$k^{w *}=k^{*} \frac{s_{w}}{s_{c}-s_{p}} \frac{H-b}{b} \quad$ and $\quad k^{c *}=k^{*}\left(1-\frac{s_{w}}{s_{c}-s_{p}} \frac{H-b}{b}\right)$

where

$k^{*}=\left(\frac{1-b}{H-b}\right)^{\frac{1}{\rho}}$ and $H=\left(\frac{n+\delta}{A b s_{C}}\right)^{\frac{\rho}{1-\rho}}$

Concerning the stability conditions for the Pasinetti equilibrium, the Jacobian matrix $J^{*}$ of the map $T$ evaluated at $\left(k^{c *}, k^{w *}\right)$ is given by

$J^{*}=J(P)=\left[\begin{array}{cc}e_{f^{\prime}}\left(k^{*}\right)\left(1-\frac{s_{w}\left(1-e_{f}\left(k^{*}\right)\right)}{e_{f}\left(k^{*}\right)\left(s_{c}-s_{p}\right)}\right)+1 & e_{f^{\prime}}\left(k^{*}\right)\left(1-\frac{s_{w}\left(1-e_{f}\left(k^{*}\right)\right)}{e_{f}\left(k^{*}\right)\left(s_{c}-s_{p}\right)}\right) \\ \frac{e_{f^{\prime}}\left(k^{*}\right)\left(\frac{s_{w}\left(1-e_{f}\left(k^{*}\right)\right.}{\left.e_{f^{\prime}\left(k^{*}\right)\left(s_{c}-s_{p}\right)}\right)}-s_{w}\right)}{s_{c}} & \frac{e_{f^{\prime}}\left(k^{*}\right)\left(\frac{s_{w}\left(1-e_{f}\left(k^{*}\right)\right)}{e_{f}\left(k^{*}\right)\left(s_{c}-s_{p}\right)}-s_{w}\right)+s_{p}}{s_{c}}\end{array}\right]$

where

$\operatorname{Tr}^{*}=-\frac{e_{f} e_{f^{\prime}} s_{w}-e_{f} s_{p}-e_{f} e_{f^{\prime}} s_{c}-e_{f} s_{c}+s_{w}\left(1-e_{f}\right) e_{f^{\prime}}}{e_{f} s_{c}}$

and

$\operatorname{Det}^{*}=-\frac{e_{f^{\prime}} s_{w}-e_{f^{\prime}} s_{p}-s_{p}}{s_{c}}$.

Then, the Pasinetti equilibrium is locally asymptotically stable if the usual stability conditions on trace and determinant [see 19] of $J_{P}$ hold, i.e. if

$$
\left\{\begin{aligned}
1-\operatorname{TrJ}^{*}+\operatorname{Det}^{*}= & \pi_{t r}=-\left[\left(1-e_{f}\right) s_{w}+e_{f}\left(s_{p}-s_{c}\right)\right]>0 \\
1+\operatorname{TrJ}^{*}+\operatorname{Det}^{*}= & \pi_{f l}=-\left[\left(1-e_{f}\right)\left(1+e_{f}\right)(\rho-1) s_{w}\right. \\
& \left.+e_{f}\left(\left(e_{f}-1\right) \rho-e_{f}-1\right)\left(s_{p}+s_{c}\right)\right]>0 \\
1-\operatorname{Det}^{*}= & \pi_{n s}=\left(1-e_{f}\right) \rho\left(s_{w}-s_{p}\right) \\
& +\left(e_{f}-1\right) s_{w}+e_{f}\left(s_{c}-s_{p}\right)+\left(1-e_{f}\right) s_{c}>0
\end{aligned}\right.
$$

Fig. 2 shows the stability region of the Pasinetti equilibrium in the $\left(s_{w}, s_{p}\right)$ plane. The red lines split up the $\left(s_{w}, s_{p}\right)$ parameter plane according to the number of the existing Solow type equilibria. In particular, the horizontal red line, denoted by $\Sigma_{1}$, refers to the condition $s_{p}=\frac{n+\delta}{A b^{1 / \rho}}$, and above such line only one Solow type equilibrium exists. Moreover, in the region bounded from above by the straight line $\Sigma_{1}$ and on the left by the curve, denoted by $\Sigma_{2}, s_{p}^{\tan }=s_{w}-\frac{(n+\delta)^{\rho}(1-\rho)^{\rho-1} s_{w}^{1-\rho}}{A^{\rho} b(-\rho)^{\rho}}$ two Solow type equilibria exist, while on the left of the latter curve and below the horizontal red line, no Solow type equilibria exist. The green lines $\Phi_{1}$ and $\Phi_{2}$ have been superimposed in order to highlight which part of the $\left(s_{w}, s_{p}\right)$ parameter plane is feasible. In particular, the feasible region is located in the portion of the plane bounded by the conditions $0<s_{p}<s_{w}<1$ and $s_{p}>s_{c} s_{w}$, i.e., in the region between $\Phi_{1}$ and $\Phi_{2}$. Finally, the grey region highlights the stability region of the Pasinetti equilibrium. In particular, the boundaries of this region are provided by the stability conditions in (16) and the crossing of each line is associated with a different type of stability loss, that can occur via Neimark-Sacker, flip or transcritical bifurcation as the black lines show in Fig. 2. More precisely, the Pasinetti

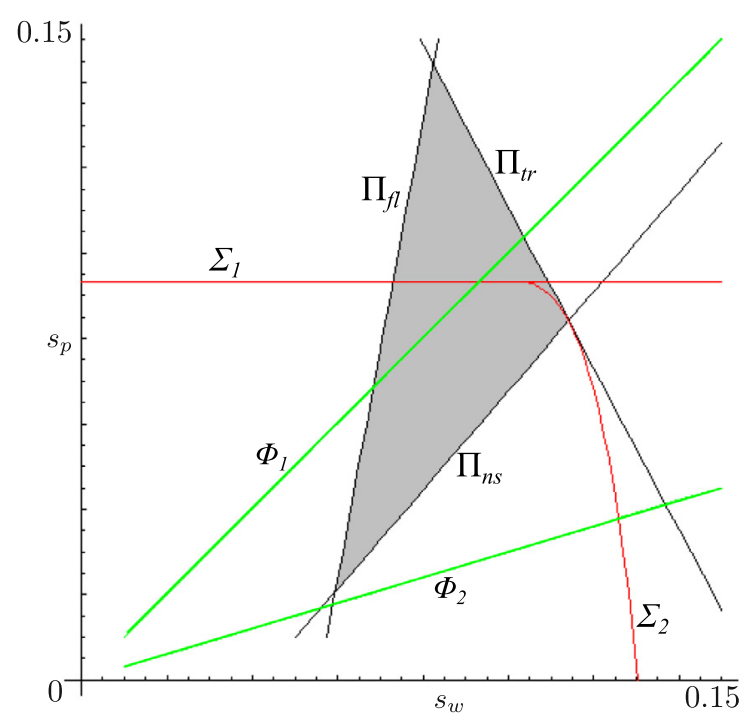

Fig. 2. Stability region (gray) of the Pasinetti equilibrium in the $\left(s_{w}, s_{p}\right)$ parameter plane for $b=0.5, A=10, \rho=-10, s_{c}=0.3, n=0$ and $\delta=1$. 


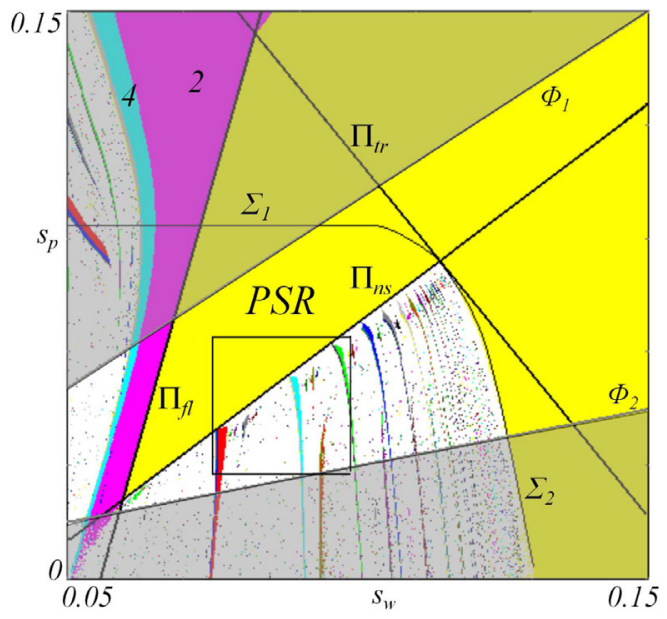

(a) 2D bifurcation diagram.

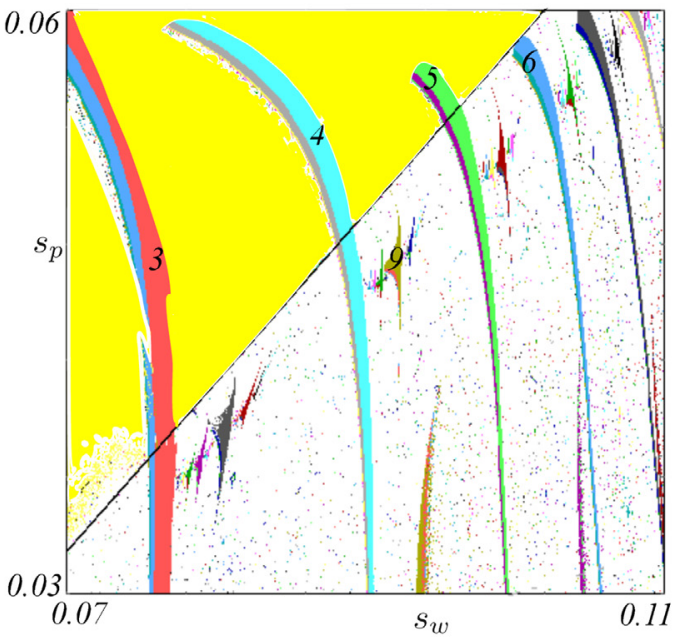

(b) Enlargement of the regions $1: n$.

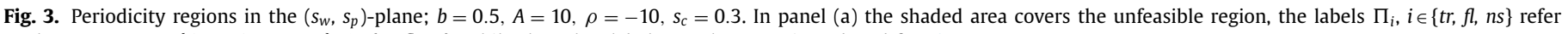
to the curves $\Pi_{i}=\left\{\left(s_{w}, s_{p}\right): \pi_{i}=0\right\}, i \in\{t r, f l, n s\}$, while the other labels are the same introduced for Fig. 2 .

equilibrium may become unstable via transcritical bifurcation when the parameters $\left(s_{w}, s_{p}\right)$ cross the curve $\pi_{t r}=0$, denoted by $\Pi_{t r}$, since it merges with a Solow steady state being $k^{c *}=0$ and equation (8) equal to equation (9), (see Proposition 1). The Pasinetti equilibrium may also be destabilized via a flip bifurcation crossing the curve $\pi_{f l}=0$, denoted by $\Pi_{f l}$, or via a NeimarkSacker bifurcation, with complex eigenvalues, crossing the curve in $\pi_{n s}=0$, denoted by $\Pi_{n s}$.

\section{Growth cycles and complex dynamics}

The remaining analysis will focus on the conditions under which the Pasinetti equilibrium loses stability and the parameters cross the curve $\pi_{n s}=0$. This is done by analyzing the global properties of the map $T$. In particular, we focus our attention on the basins of attraction of the coexisting attractors and on their structural changes due to the occurrence of global bifurcations. In the following analysis, we consider a constant size of the two groups of agents, i.e. $n=0$, and full depreciation, i.e. $\delta=1$.

We start presenting a 2D bifurcation diagram in the $\left(s_{w}, s_{p}\right)$ parameter plane to illustrate the overall bifurcation structure. In fact, Fig. 3(a) shows such a diagram marking the yellow region as the one in which a stable steady state exists (inside the region PSR the Pasinetti equilibrium, outside a Solow one), the other colors are related to attracting cycles of different periods and the white region corresponds either to chaotic attractors or to cycles of higher periodicity. Moreover, the Pasinetti equilibrium may lose stability also via flip bifurcation, crossing into the region colored in purple associated with a cycle of period 2 , arising when such equilibrium is destabilized.

In the region where no Solow equilibrium exists, the characteristic shape ${ }^{4}$ of periodicity regions, emanating from the curve $\pi_{n s}=$ 0 , is clearly visible. These curves resemble the Arnold tongues, which typically emanate from a Neimark-Sacker bifurcation curve, whose boundaries are saddle-node bifurcation curves and the issuing point from the Neimark-Sacker curve is generally a cusp

\footnotetext{
${ }^{4}$ We refer to a tongue-shaped region that first appears narrow in the vicinity of the Neimark-Sacker bifurcation curve and then widens and opens out, sometimes overlapping. In fact, such tongues do not overlap as far as the parameters are close to the bifurcation curve, while they may overlap when the parameters are taken far enough from the bifurcation curve, denoting an increase of nonlinearity. On this topic we refer to $[1,4,10,18,26]$.
}

point (except for the strong resonance cases 1: $n, n=1,2,3,4$ ). More precisely, the boundaries of an $m / n$ tongue ${ }^{5}$ issuing from a Neimark-Sacker bifurcation curve are saddle-node bifurcation curves of a pair of $n$-cycles, and inside the tongue an attracting closed invariant curve may exist, made up by a saddle-node connection of the $n$-cycle. Between two tongues issuing from a Neimark-Sacker bifurcation curve of periodicity $m_{1} / n_{1}$ and $m_{2} / n_{2}$ a particular (Farey) summation rule applies (see e.g. [9,17]), and the tongue with periodicity $\left(m_{1}+m_{2}\right) /\left(n_{1}+n_{2}\right)$ exists as well. The enlargement of Fig. 3(b) illustrates a particular features of the periodicity regions, due to a change in the initial conditions. Namely, the regions related to the rotation number $1 / n$ intersect the stability region of the Pasinetti equilibrium (thus signaling the possibility of attractors coexistence) and the corresponding Arnold tongues are their subset. Moreover, one of the boundary of each of these periodicity regions is a flip bifurcation curve and, accordingly, we can observe a period doubling bifurcation followed by a Feigenbaum cascade. Hence, a possible dynamic behavior that immediately arises is the coexistence of different attractors corresponding to a situation in which capital fluctuations, eventually chaotic, coexist with trajectories dumping towards the Pasinetti equilibrium.

An example for which the Pasinetti equilibrium coexists with a cycle is first detected through the 2D bifurcation diagram reported in Fig. 4(a), where we observe the intersection of the tongue associated to the 3-cycle with the stability region of the steady state. And the corresponding attractors coexistence is reported in Fig. 4b, where we depict the basin of attraction of the Pasinetti equilibrium $P^{*}$ in yellow and the basin of the 3 -cycle $D$ in red. In particular, we observe that the basins of the two attractors are separated by the stable set of the period 3 saddle-cycle which has a complicated structure due to many oscillations occurring in a region quite far from $P^{*}$. Then, if the value of the parameter $s_{p}$ is diminished, the phase space depicted in Fig. 4(c) suggests that the Pasinetti equilibrium loses stability via a supercritical Neimark-Sacker bifurcation and an attracting closed invariant curve appears, surrounding the unstable fixed point. In fact, in Fig. 4(c) the basin of attraction of the cycle $D$ is still shown in red while the basin of the closed invariant curve $\Psi$ is in yellow. On the other hand, if we still re-

\footnotetext{
${ }^{5}$ We recall that the integer $n$ denotes the period of the cycle while $m$ denotes the number of laps around the fixed point which are necessary to complete the whole orbit.
} 


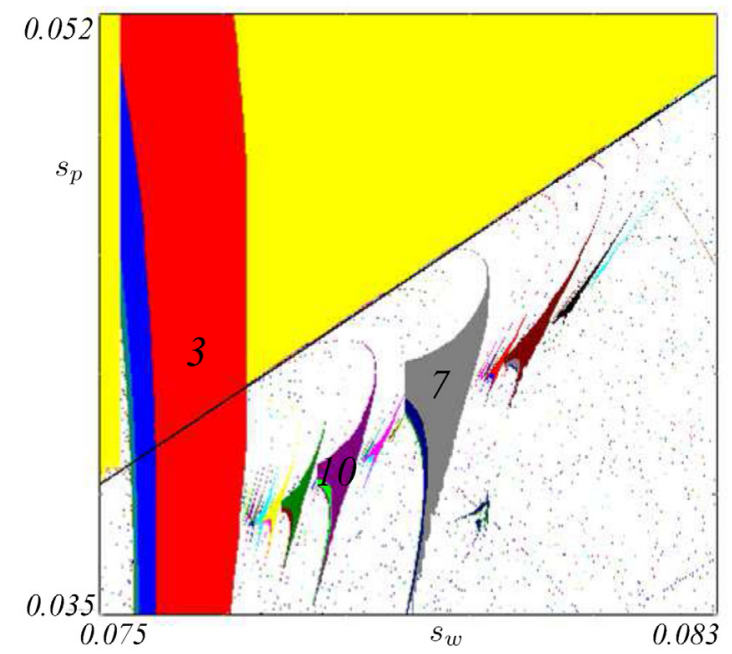

(a) Intersection of the period 3 region with the stability region of the Pasinetti equilibrium

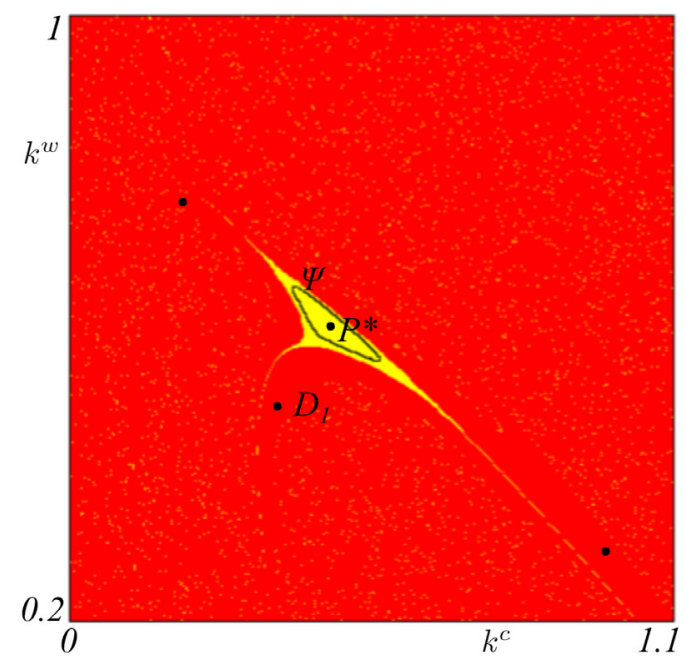

(c) After the NS bifurcation, $D$ coexists with an attracting closed invariant curve $\Psi . s_{p}=0.0402$, $s_{w}=0.0765$

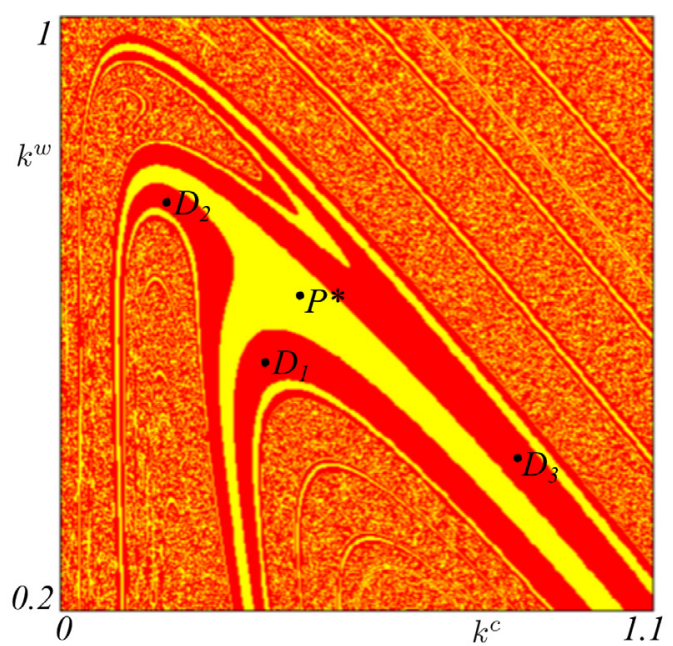

(b) Coexistence of $P^{*}$ and a 3-cycle $D . s_{p}=0.052$, $s_{w}=0.0765$

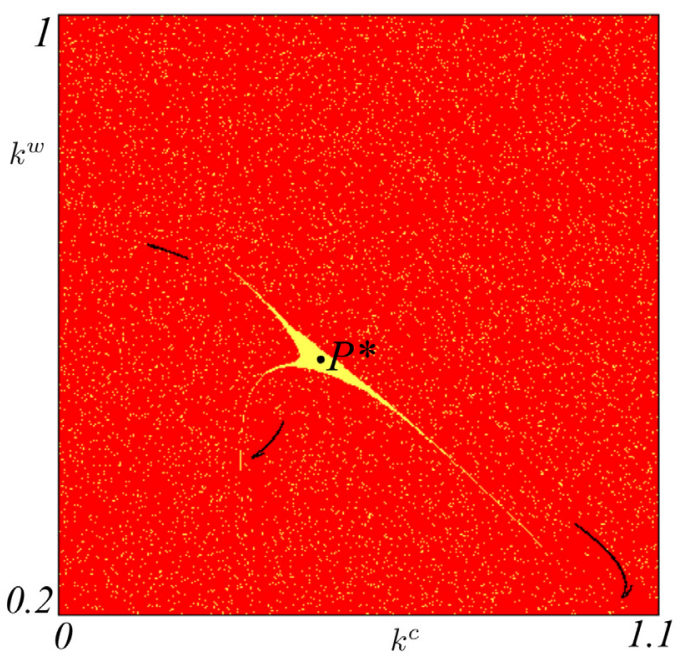

(d) $P^{*}$ coexists with a three pieces chaotic attractor. $s_{p}=0.0402, s_{w}=0.0754$

Fig. 4. Multistability associated with a period 3 cycle; $b=0.5, A=10, \rho=-10, s_{c}=0.3$.

main within the stability region of $P^{*}$ and we exit the periodicity region from the flip bifurcation boundary, we observe a situation in which the Pasinetti equilibrium coexists with a three pieces chaotic attractor as portrayed in Fig. 4(d). This occurs after the previously existing 3-cycle has undergone its period doubling cascade with the consequent route to chaotic dynamics.

Fig. 5 displays the basins of attraction of three coexisting attractors, still inside the periodicity region associated with the cycle of period 3: namely an attracting closed invariant curve, whose basin is depicted in yellow, a cycle of period 3, with the corresponding basin in red, and a chaotic attractor with its basin in white. The enlargement of Fig. 5(b) allows us to observe better the shape of the chaotic attractor, which is made by several pieces and additionally, such an attractor is very close to its basin boundary. This signals the occurrence of an incoming contact bifurcation. In fact, as we slightly increase the value of $s_{p}$, the chaotic attractor disappears and the coexistence is now among two cycles, $F$ and $G$, and the closed invariant curve which still exists (even if not visible in Fig. 5(c)).

Finally, a further situation of multistability may appear as the coexistence of cycles of different periodicity, since the Arnold tongues may intersect among them too (see Fig. 6a, showing the intersections of the tongues associated with the 9-cycle and the 13-cycle). An example is portrayed in the phase plane of Fig. 6(b) in which, fixing the values $s_{c}=0.3$ and $s_{w}=0.09119$, it is possible to observe a stable 9-cycle coexisting with a stable 13-cycle, while the Pasinetti equilibrium, denoted with $P^{*}$, is unstable. The periodic points of these cycles are illustrated in the $\left(k_{c}, k_{w}\right)$ phase plane as well as their basins of attractions: the blue color is used for the basin of the 9-cycle while the yellow color refers to the basin of the 13-cycle. The complicated basin structure resembles the one portrayed in Fig. 4(b) due to the oscillations that take place in a region far from the Pasinetti equilibrium.

\subsection{Appearance/disappearance of closed invariant curve}

The occurrence of a Neimark-Sacker bifurcation has significant consequences both from an economic and a mathematical point of view. The real financial and economic systems show a lot of complex dynamical phenomena, such as, business cycle, financial crisis and irregular growth. In particular, when a Neimark-Sacker bifurcation occurs, a steady growth can turn into quasi-periodic and 


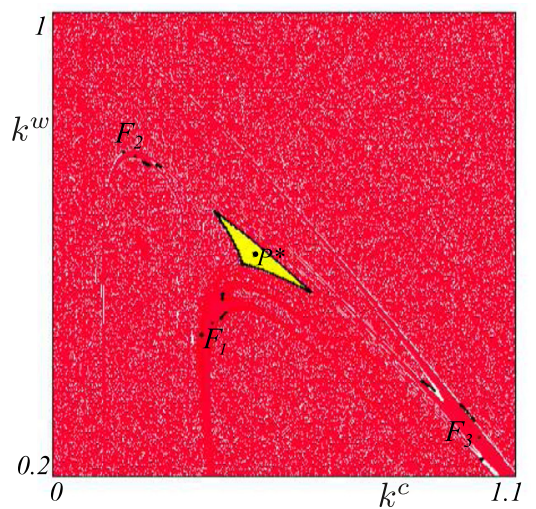

(a) A closed invariant curve, a chaotic attractor, a 3-cycle $F . s_{p}=0.03951$

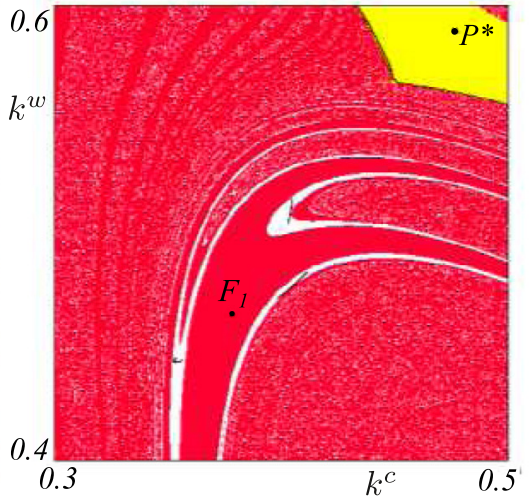

(b) Enlargement. $s_{p}=0.03951$

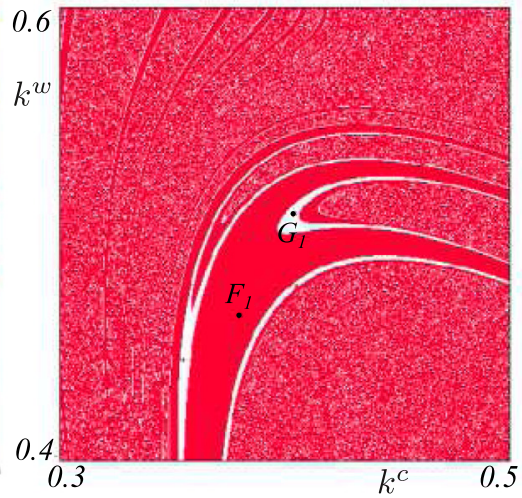

(c) The two stable cycles, $F$ and $G$, coexist. $s_{p}=0.03948$

Fig. 5. Coexistence of three different attractors: $b=0.5, A=10, \rho=-10, s_{c}=0.3$ and $s_{w}=0.076$.

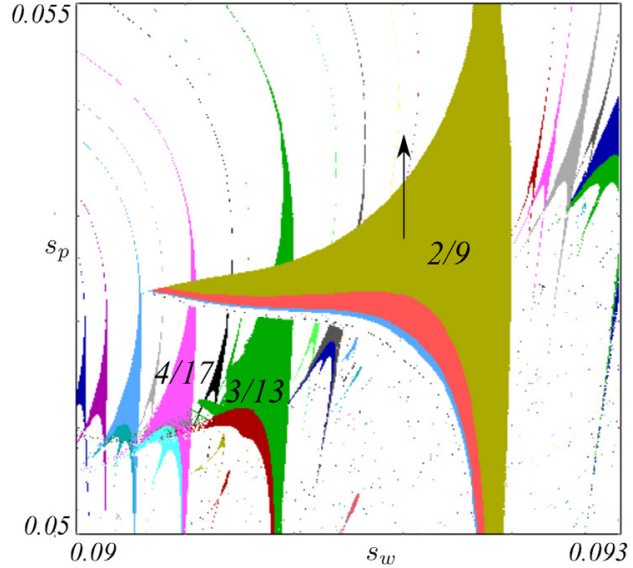

(a) Intersection of the tongues associated with period 9 and period 13 cycles.

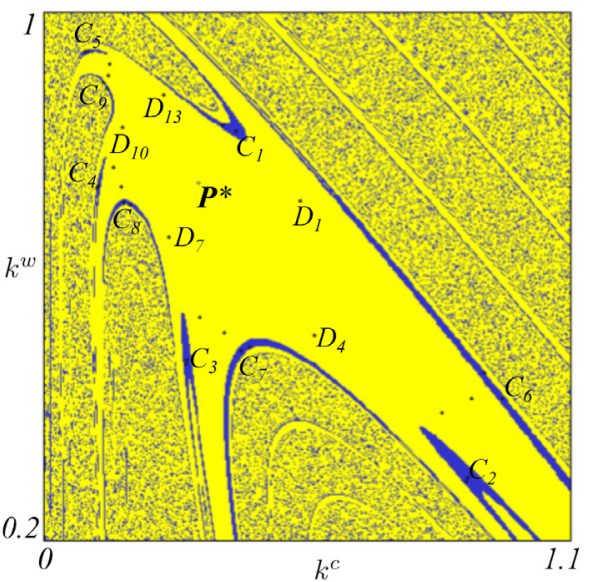

(b) Basin of the 9-cycle $C$ (blue) and the 13-cycle $D$ (yellow). $s_{p}=0.05225$

Fig. 6. Coexistence of different cycles: $b=0.5, A=10, \rho=-10, s_{c}=0.3$ and $s_{w}=0.09119$.

then, at least for some parameter combinations related to the different saving propensities, into complex dynamics. Moreover, even if a Neimark-Sacker bifurcation may not have global effects (in the sense that after the bifurcation the trajectories of the points close to the unstable focus reach the attracting closed curve), it may also be the case the homoclinic tangencies and homoclinic tangles of saddles arise in the transition from local regular to global irregular fluctuations, due to the increased complexity of the attractors. Then, if the map exhibits some multistability phenomena, as is the case of the present work, the invariant closed curve may interact with other attractors and interesting dynamic phenomena may occur, often associated with homoclinic or heteroclinic tangles. These are the motivations at the ground of the analysis that we shall carry on in this subsection.

We proceed in our analysis by investigating what happens when the boundary of the Arnold tongue associated with the cycle of period 9 is crossed, as the bifurcation path, marked by an arrow, indicates in Fig. 6(a). In fact, differently from the previous case, this is effectively an Arnold tongue, as it issues from the NeimarkSacker bifurcation curve from a cusp point. To do so, we fix the values of the saving propensities $s_{c}=0.3$ and $s_{w}=0.092$, while we decrease the values of the parameter $s_{p}$. For this purpose, Fig. 7 turns out to be useful in explaining the global bifurcations associated with the appearance/disappearance of an invariant closed curve when the parameter $s_{p}$ is varied.
When we cross the bifurcation boundary of the Arnold tongue from above, a 9-cycle appears and coexists with the attracting closed curve $\Gamma$ associated to a supercritical Neimark-Sacker bifurcation. The 9-cycle arises via saddle-node bifurcation along with a saddle cycle and the boundary of its basin is given by the stable set of the saddle cycle, as shown in Fig. 7(a). As we further decrease $s_{p}$, the attracting closed curve is replaced by a saddle-focus connection, that is, the stable cycle turned into a focus still coexists with a saddle cycle of period 9 , and its periodic points are connected by the unstable set of the saddle cycle, as shown in Fig. 7(b). In this figure we have considered the ninth iterate of the map in order to emphasize the behavior of the stable set of the saddle $^{6}$ which exhibits more oscillations far from the Pasinetti equilibrium while in the proximity of the closed curve it has a smooth behavior.

We now investigate how the closed curve disappears as long as $s_{p}$ varies in order to discover whether any homoclinic tangle may be involved, as suggested by the enlargement of Fig. 7(c). In fact, in such a figure we observe that the stable set of the saddle is very close to the closed curve, at which a branch of its unstable set converges. This denotes that a qualitative change in the structure of the basin and in the nature of the attractor is going

\footnotetext{
${ }^{6}$ We recall that the stable sets of the saddles separate the basin of the nine fixed points of the map $T^{9}$.
} 

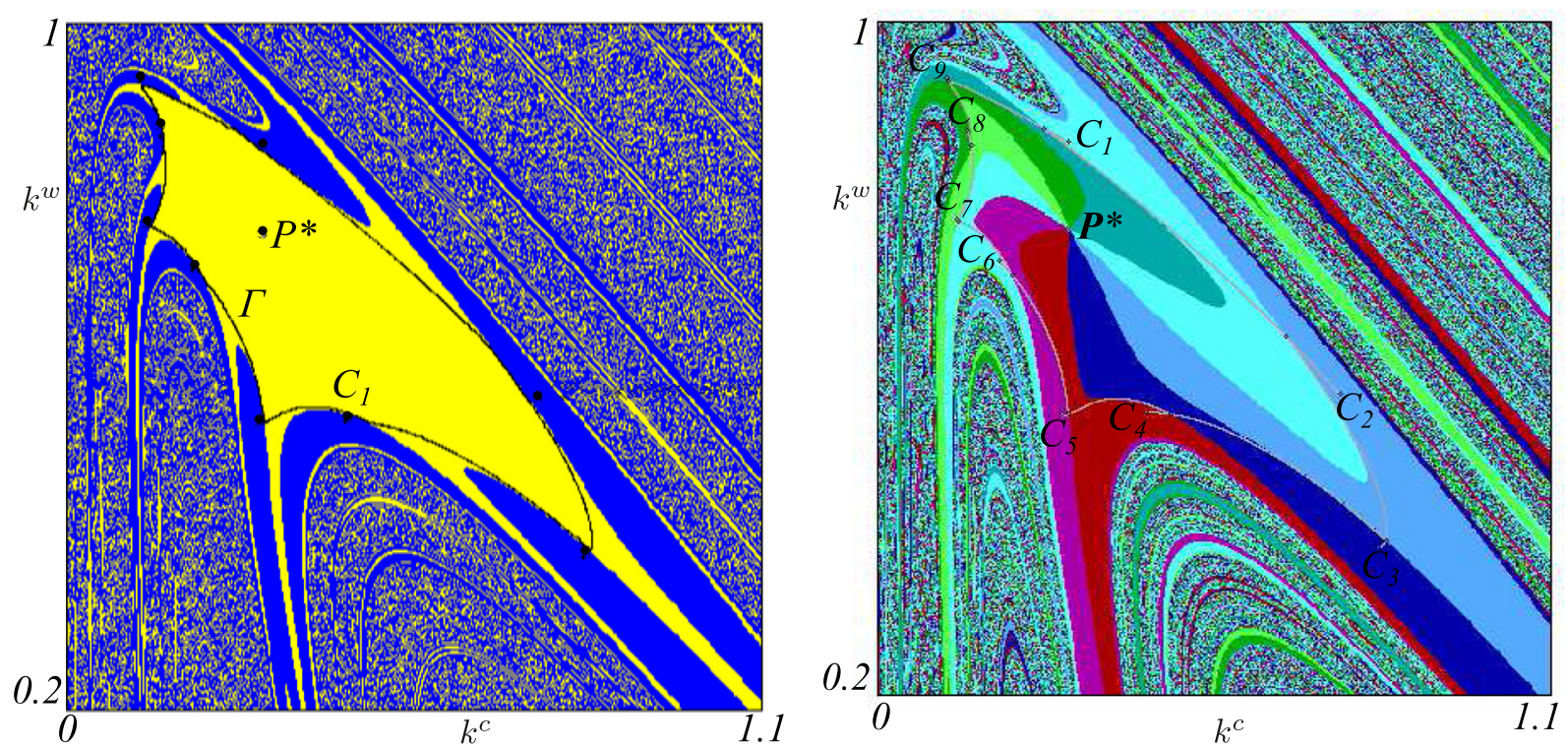

(a) Coexistence of a closed invariant curve with a 9-cycle.(b) A saddle-focus connection replaces the closed curve. $s_{p}=0.05378$ $s_{p}=0.05375$

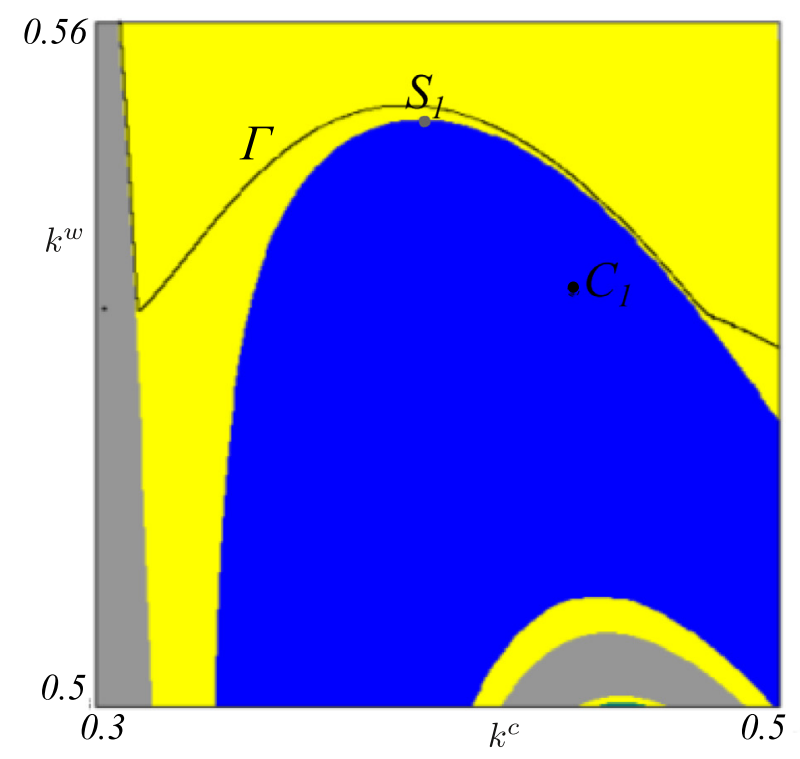

(c) Enlargement around $C_{1}$

Fig. 7. Dynamics at the exit of the period 9 tongue; $b=0.5, A=10, \rho=-10, s_{c}=0.3, s_{w}=0.092$.

to occur, namely the disappearance of the curve. In order to prove the occurrence of a global bifurcation we consider the phase space obtained with an intermediate value of $s_{p}$ (see Fig. 8(a)). In this figure, we notice the appearance of a fractal structure in the region previously covered by the basin of the attracting closed curve, and this is due to a homoclinic bifurcation illustrated in the enlargements of Fig. 8. Looking at the enlargement of Fig. 8(b), the stable set of the saddle associated with the cycle $C$ starts exhibiting some oscillations and approaches the invariant closed curve, with the occurrence of a homoclinic tangency between the stable set of the saddle-cycle and the curve. Then, as the parameter $s_{p}$ decreases slightly more, the oscillations become more and more pronounced (see Fig. 8(b)) giving rise to the homoclinic tangle; finally, as $s_{p}$ is further reduced, a second reverted homoclinic tangency occurs and no points of the unstable set of the saddle converge to the curve, which has now disappeared, as Fig. $8(\mathrm{c})$ highlights.

\section{Concluding remarks}

Growth models are instrumental for explaining long term economic performance. These models generally lead to long term growth scenarios that may or may not include the possibility of cycles and endogenous fluctuations. In this paper we have considered a standard neoclassical growth model along the lines of Kaldor, Pasinetti and others, which was extended to allow for ownership of capital among OLG consumers of workers and capitalists as well as different savings propensities among agents. The results of our analysis show that the interaction of the nonlinear income distribution with heterogeneous logarithmic intertemporal preferences of consumers causes a variety of local bifurcation scenarios, multistability, as well as a rich variety of complex global dynamic features. Fluctuations in this model originate from the different savings behaviors, $s_{w} \neq s_{p} \neq s_{c}$, and from the features of technology related to the elasticity of substitution, which is a specific 


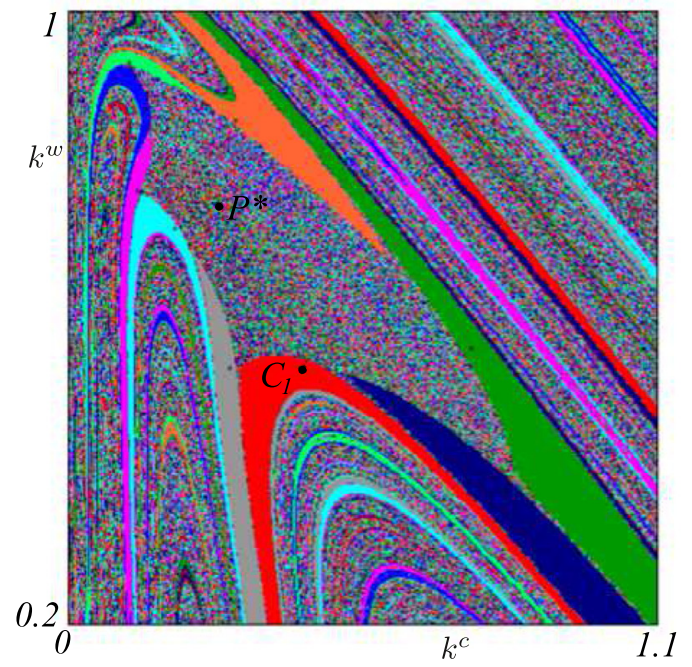

(a) Fractal basins. $s_{p}=0.05376$

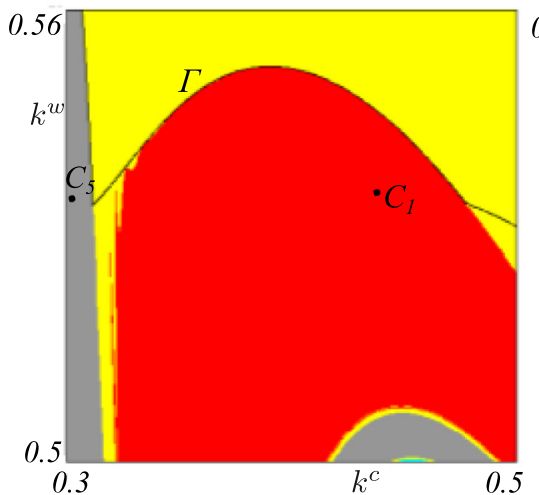

(b) First tangency. $s_{p}=0.05376003$

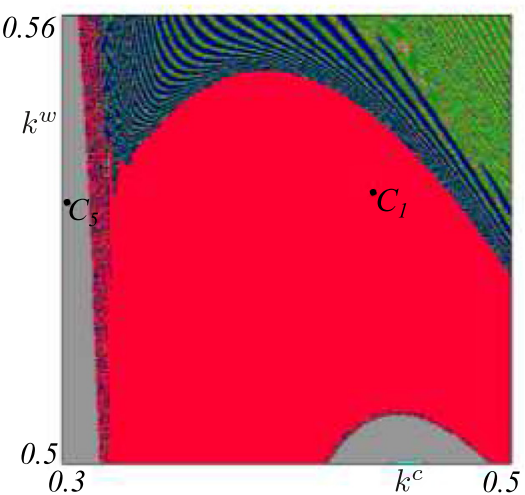

(c) Homoclinic tangle. $s_{p}=0.0537599$

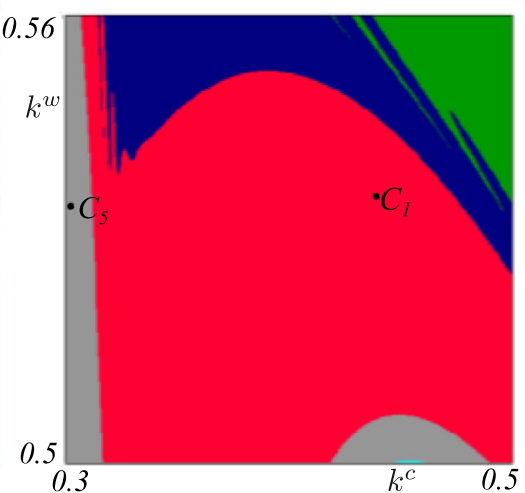

(d) Closure of the tangle. $s_{p}=0.0537598$

Fig. 8. Homoclinic bifurcation associated with the disappearance of the closed curve; $b=0.5, A=10, \rho=-10, s_{c}=0.3$ and $s_{w}=0.09119$.

feature of the employed CES production function. From the mathematical viewpoint, besides the typical convergence to a steady state, we have shown that complicated endogenous dynamics such as growth cycles and even chaotic dynamics characterize a large portion of the parameters space. In particular, the coexistence of different attractors is of relevance since the Arnold tongues associated with 1: $n$ cycles are contained in wider periodicity regions crossed by the Neimark-Sacker bifurcation curve. This phenomenon is quite generic in presence of subcritical Neimark-Sacker bifurcation, but this is not the case here. Moreover, it is also noteworthy that one boundary of these periodicity regions is made up by a flip bifurcation curve, opening the onset of chaotic attractors coexisting with the stable Pasinetti equilibrium.

\section{Declaration of Competing Interest}

The authors declare that they have no known competing financial interests or personal relationships that could have appeared to influence the work reported in this paper.

\section{Acknowledgments}

We wish to thank two anonymous referees for their valuable comments and suggestions. The usual caveats apply.

This research did not receive any specific grant from funding agencies in the public, commercial, or not-for-profit sectors.

\section{References}

[1] Agliari A, Bischi G-I, Dieci R, Gardini L. Global bifurcations of closed invariant curves in two-dimensional maps: a computer assisted study. Int J Bifurc Chaos 2005;15(04):1285-328.

[2] Arrow K, Chenery H, Minhas B, Solow R. Capital-labor substitution and economic efficiency. Rev Econ Stat 1961;43:225-50.

[3] Böhm V, Kaas L. Differential savings, factor shares, and endogenous growth cycles. J Econ Dyn Control 2000;24:965-80.

[4] Boyland PL. Bifurcations of circle maps: Arnol'd tongues, bistability and rotation intervals. Commun Math Phys 1986;106(3):353-81.

[5] Brianzoni S, Mammana C, Michetti E. Complex dynamics in the neoclassical growth model with differential savings and non-constant labor force growth. Stud Nonlinear Dyn Econom 2007;11(3).

[6] Brianzoni S, Mammana C, Michetti E. Nonlinear dynamics in a business-cycle model with logistic population growth. Chaos Solitons Fractals 2009:40:717-30.

[7] Commendatore P, Palmisani C. The pasinetti-solow growth model with optimal saving behaviour: a local bifurcation analysis. In: Topics On Chaotic Systems: Selected Papers from CHAOS 2008 International Conference. World Scientific; 2009. p. 87-95.

[8] Diamond P. National debt in a neoclassical growth model. Am Econ Rev 1965;55(5):1126-50.

[9] Farey J. Lxxix. on a curious property of vulgar fractions. Philos Mag 1816;47(217):385-6.

[10] Gumowski I, Mira C. Dynamique chaotique: transformations ponctuelles, transition, ordre-désordre (1980)

[11] Harrod R. An essay in dynamic theory. Economic Journal 1939;49:14-33.

[12] Kaldor N. Alternative theories of distribution. Rev Econ Stud $1955 ; 23(2): 83-100$.

[13] Kaldor N. A model of economic growth. Econ J 1957;67:591-624.

[14] Kaldor N. Capital accumulation and economic growth. In: Lutz FA, Hague DC, editors. Proceedings of a conference held by the international economic association. London: Macmillan; 1963. 
[15] Klump R, de La Grandville O. Economic growth and the elasticity of substitution: two theorems and some suggestions. Am Econ Rev 2000;90(1):282-91.

[16] Klump R, Preissler H. Ces production functions and economic growth. Scand J Econ 2000;102(1):41-56.

[17] Leonov N. Map of the line onto itself. Radiofisica 1959;3(3):942-56.

[18] Maistrenko V, Maistrenko Y, Mosekilde E. Torus breakdown in noninvertible maps. Phys Rev E 2003;67(4):046215.

[19] Medio A, Lines M. Nonlinear dynamics: a primer. Cambridge University Press; 2001.

[20] Miyagiwa K, Papageorgiou. Elasticity of substitution and growth: normalized ces in the diamond model. Econ Theory 2003;21(1):155-65.

[21] Pasinetti LL. Rate of profit and income distribution in relation to the rate of economic growth. Rev Econ Stud 1962;29:267-79.
[22] Samuelson PA. An exact consumption-loan model of interest with or without the social contrivance of money. J Pol Econ 1958;66(6):467-82.

[23] Samuelson PA, Modigliani F. The pasinetti paradox in neoclassical and more general models. Rev Econ Stud 1966;33:269-301.

[24] Solow RM. A contribution to the theory of economic growth. Q J Econ 1956;70(1):65-94.

[25] Stiglitz JE. Distribution of income and wealth among individuals. Econometrica 1969;37:382-97.

[26] Sushko I, Puu T, Gardini L. The hicksian floor-roof model for two regions linked by interregional trade. Chaos Solitons Fractals 2003;18(3):593-612.

[27] Swan TW. Economic growth and capital accumulation. Econ Record $1956 ; 32: 334-61$.

[28] Ventura J. Growth and interdependence. Q J Econ 1997;112(1):57-84. 